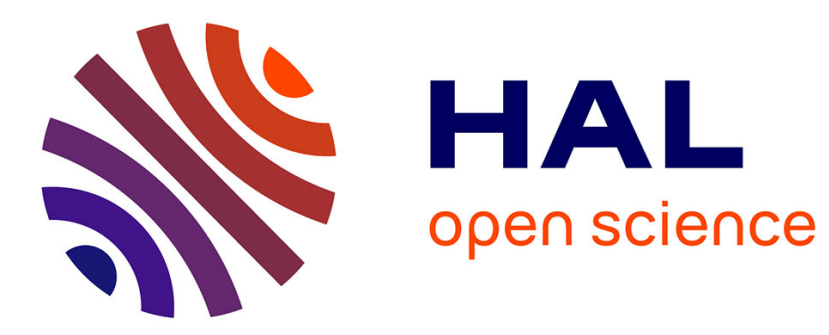

\title{
Tailoring of elastomeric grafted coating via sol-gel chemistry of crosslinked polymethylhydrosiloxane
}

T. Thami, B. Bresson, Christian Frétigny

\section{To cite this version:}

T. Thami, B. Bresson, Christian Frétigny. Tailoring of elastomeric grafted coating via sol-gel chemistry of crosslinked polymethylhydrosiloxane. Journal of Applied Polymer Science, 2007, 104 (3), pp.15041516. 10.1002/app.25295. hal-00164881

\section{HAL Id: hal-00164881 \\ https://hal.science/hal-00164881}

Submitted on 18 Nov 2020

HAL is a multi-disciplinary open access archive for the deposit and dissemination of scientific research documents, whether they are published or not. The documents may come from teaching and research institutions in France or abroad, or from public or private research centers.
L'archive ouverte pluridisciplinaire HAL, est destinée au dépôt et à la diffusion de documents scientifiques de niveau recherche, publiés ou non, émanant des établissements d'enseignement et de recherche français ou étrangers, des laboratoires publics ou privés. 


\title{
Tailoring of Elastomeric Grafted Coating via Sol-Gel Chemistry of Crosslinked Polymethylhydrosiloxane
}

\author{
Thierry Thami, ${ }^{1}$ Bruno Bresson, ${ }^{2}$ Christian Fretigny ${ }^{3}$ \\ ${ }^{1}$ Institut Européen des Membranes, CNRS UMR 5635 UMII, Place Eugène Bataillon, CC047, \\ 34090 Montpellier Cedex 5, France \\ ${ }^{2}$ LPQ/ESPCI, CNRS UMR 7142, 10 rue Vauquelin, 75231 Paris cedex 05, France \\ ${ }^{3}$ PPMD/ESPCI, CNRS UMR 7615, 10 rue Vauquelin, 75231 Paris cedex 05, France
}

Received 19 December 2005; accepted 3 August 2006

DOI 10.1002/app.25295

Published online in Wiley InterScience (www.interscience.wiley.com).

\begin{abstract}
Thin coating of crosslinked polymethylhydrosiloxane are grafted on silica using sol-gel process that leads to polymer layers tailored in term of thickness and elasticity. The degree of crosslinking is tuned by solgel polycondensation of a mixture of methyldiethoxysilane $(\mathrm{DH}) \mathrm{HSi}\left(\mathrm{CH}_{3}\right)\left(\mathrm{OCH}_{2} \mathrm{CH}_{3}\right)_{2}$ and triethoxysilane $(\mathrm{TH})$ $\mathrm{HSi}\left(\mathrm{OCH}_{2} \mathrm{CH}_{3}\right)_{3}$, yielding triethoxysilane-based networks. Samples with well-defined thicknesses from nanometer to micrometer range are prepared by sol-gel dip-coating method on silicon surface. Homogeneous or gradientthickness coating can be produced in this way. It results in surface-attached networks bearing $\mathrm{Si}-\mathrm{H}$ functionalities covalently anchored to the substrate. Powdered gels of DH/
\end{abstract}

TH composition from $50 / 50$ to $95 / 5$ (mol \%) were also prepared for a comparison purpose. The structure of the gels was investigated by NMR and FTIR, showing that $\mathrm{DH} / \mathrm{TH}$ mixtures react totally to yield homogeneous matrix. The surface-attached polymer films are very stable and present high hydrophobicity as evidenced by contact angle measurements. Their surface and mechanical properties have been qualitatively studied using the atomic force microscopy. (c) 2007 Wiley Periodicals, Inc. J Appl Polym Sci 104: 1504-1516, 2007

Key words: thin films; crosslinking; sol-gel process; dipcoating; elastomers

\section{INTRODUCTION}

Polymer coating of surfaces is of great importance in many industrial applications. It is then a challenge to synthesize polymeric thin films with well-defined thickness, elastic properties, and a good adhesion to the substrate.

An important chemical pathway for preparing thin films at room temperature is the hydrolytic polycondensation of silicon alkoxide monomers $R_{n} \mathrm{Si}\left(\mathrm{OR}^{\prime}\right)_{4-n}$ ( $n=1$ or $2 ; R$ is currently an organic group), so called sol-gel process. Our interest was focused on $\mathrm{SiH}$-substituted silicon alkoxide precursors $(\mathrm{R}=\mathrm{H})$, because they have high reactivity toward sol-gel process ${ }^{1-4}$ by contrast with precursors substituted with bulky organic groups ${ }^{5}$ often used as coupling agents. ${ }^{6}$ Sorarù et al. reported that mixtures of trifunctional triethoxysilane $\mathrm{HSi}(\mathrm{OEt})_{3}(\mathrm{TH})$ and difunctional methyldiethoxysilane $\mathrm{HSiMe}(\mathrm{OEt})_{2}(\mathrm{DH})$ were reacted totally to lead homogeneous bulk gel without phase separation. ${ }^{4}$ The condensation is thus often totally completed in the

Correspondence to: T. Thami (thierry.thami@iemm.univmontp2.fr).

Contract grant sponsors: Ministère de la Recherche (ACI Grant) and CNRS.

Journal of Applied Polymer Science, Vol. 104, 1504-1516 (2007) C 2007 Wiley Periodicals, Inc.

\section{(\$)WILEY}

final bulk gel, which, as a consequence, contains no or few amount of unreacted silanol $\mathrm{SiOH}$ or $\mathrm{SiOEt}$ groups. The elastic properties of the bulk gels can be thus easily controlled with the ratio of difunctional and trifunctional monomers $(\mathrm{DH} / \mathrm{TH})$. The resulting crosslinked networks in these bulk gels have been described as copolymer formed by polymethylhydrosiloxane (PMHS) chains $\mathrm{SiH}\left(\mathrm{CH}_{3}\right) \mathrm{O}_{2 / 2}$ interconnected by randomly dispersed $\mathrm{SiHO}_{3 / 2}$ subunits. ${ }^{4}$

Preparing grafted elastomeric thin film with $\mathrm{Si}-\mathrm{H}$ functionalities provides an attractive route to taylor elastomeric polysiloxanelike thin film: Indeed the attachment to the surface (such as silica) and the solgel polycondensation can be performed in one step and using an adequate mixture of the di- and trifunctional silicon alkoxide monomers $(n=1$ and 2$)$ allows to adjust the polymer network properties. Moreover, surface bearing $\mathrm{Si}-\mathrm{H}$ functionalities also interestingly have potential for further chemical modification of the surface by postfunctionalization via hydrosilation with alkene, ${ }^{7,8}$ allowing immobilization of receptor molecules into membranes with controlled mesh size for separation and sensing.

In this context, the aim of this study was to tailor elastomeric thin film in term of elasticity, and thickness via hydrolysis and condensation of $\mathrm{DH} / \mathrm{TH}$ mixture. Thin films based on crosslinked PMHS were prepared on freshly activated silica surface of a sili- 
con wafer, using dip-coating. The main difficulty of this kind of synthesis is to make a good DH/TH dispersion of the gel and to avoid remaining $\mathrm{SiOR}$ or $\mathrm{SiOH}$ groups corresponding to incomplete reaction. In this respect, a large part of this article is devoted to the study of the gel structure. Aging and reactivity of the $\mathrm{DH} / \mathrm{TH}$ starting sols before thin film preparation were controlled, first. We then focused on the corresponding $\mathrm{DH} / \mathrm{TH}$ powdered gels in similar condition as dip-coating experiments to control the microstructure of the final DH/TH gels. Thin films were finally fabricated from controlled aging sols of various $\mathrm{DH} / \mathrm{TH}$ monomers ratio. The thicknesses and chemical stability of the dip-coated thin films have been characterized. Experimental results qualitatively show that, as expected, mechanical properties may easily be tuned by changing the $\mathrm{DH} / \mathrm{TH}$ ratio.

\section{EXPERIMENTAL}

\section{Materials}

Both precursors methyldiethoxysilane $\mathrm{HSi}\left(\mathrm{CH}_{3}\right)$ $\left(\mathrm{OCH}_{2} \mathrm{CH}_{3}\right)_{2}$ and triethoxysilane $\mathrm{HSi}\left(\mathrm{OCH}_{2} \mathrm{CH}_{3}\right)_{3}$ were purchased from $\mathrm{ABCR}$ (Karlsruhe, Germany) and used as received. Absolute ethanol (SDS) was dried and stored on $4 \AA$ molecular sieve before being used in sol-gel synthesis. The catalyst trifluoromethanesulfonic acid $\mathrm{CF}_{3} \mathrm{SO}_{3} \mathrm{H}$ (Aldrich, Germany) was dissolved in absolute $1 M$ ethanol. Water used throughout this study was purified with a Milli-Q water purification system (Millipore). The substrates used for ellipsometry and FTIR measurements were silicon (100) wafers (MEMC Electronic materials, Italy). For thin films preparation, the silicon wafers were used in the form of native oxide layer and were cut into smaller rectangular strips of about $2 \times 2.5 \mathrm{~cm}^{2}$. All solvents, $\mathrm{CHCl}_{3}$, $\mathrm{CCl}_{4}$, toluene, or $n$-hexane, used were of synthesis grade purity from SDS and were employed as supplied for the washing procedure of films.

\section{Powders preparation}

The various $\mathrm{DH} / \mathrm{TH}$ powders prepared from bulk gel samples are listed in Table I. The mixture of the two alkoxide monomers were polymerized in various molar compositions $\mathrm{DH} / \mathrm{TH}$ ranging from 50/50 to $95 / 5$ (mol \%) in $\mathrm{EtOH}$ as reactant solvent at about $4 M$ concentration (molar ratio relative to monomers concentration $[\mathrm{EtOH}] /[\mathrm{Si}]=1)$. Trifluoromethanesulfonic acid $\mathrm{CF}_{3} \mathrm{SO}_{3} \mathrm{H}$ (1M in absolute ethanol) was used as catalyst $(0.05-0.3 \mathrm{~mol} / \mathrm{mol} \%$ relative to monomers concentration). The hydrolysis ratio $\left(h=\left[\mathrm{H}_{2} \mathrm{O}\right] /\right.$ $[\mathrm{SiOEt}]=0.5)$ was constant in all experiments. This corresponds to the theoretical stoichiometry to achieve a complete hydrolysis and condensation of a mixture $\alpha / 1-\alpha$ of $\mathrm{DH} / \mathrm{TH}$ according to the usual hydrolysis and condensation reactions in sol-gel process:

$$
\begin{aligned}
\alpha \mathrm{HSi}\left(\mathrm{CH}_{3}\right)(\mathrm{OEt})_{2}+ & (1-\alpha) \mathrm{HSi}(\mathrm{OEt})_{3} \\
+(3-\alpha) / 2 \mathrm{H}_{2} \mathrm{O} & \rightarrow\left[\mathrm{SiH}\left(\mathrm{CH}_{3}\right) \mathrm{O}_{2 / 2}\right]_{\alpha}\left[\mathrm{SiHO}_{3 / 2}\right]_{1-\alpha} \\
+ & (3-\alpha) \mathrm{EtOH}
\end{aligned}
$$

All experiments were performed at least in duplicate. These mixtures react very fast as expected with alkoxide precursors bearing $\mathrm{Si}-\mathrm{H}$. In Table I, the different values of the gelation time $t_{\text {gel }}$ indicate some kinetic variations due to various catalyst amounts and $\mathrm{DH} / \mathrm{TH}$ monomers ratio. Typical sol-gel procedure was as follows: In a mixture $\alpha / 1-\alpha$ of the monomers $\mathrm{DH} / \mathrm{TH}$, the solvent $\mathrm{EtOH}$, the catalyst $\mathrm{CF}_{3} \mathrm{SO}_{3} \mathrm{H}(1 \mathrm{M}$ in $\mathrm{EtOH})$, and then water were added under vigorous stirring in the appropriate amounts according to the Reaction (1). The resulting clear sols were aging under magnetic stirring until gelation occurs. After drying in air at room temperature, bulk samples were obtained. Because of the relatively slow kinetics of solvents releasing, bulk gel samples were first air-dried several days before grinding into fine powders in an agate mill. Powders were then air-dried for about 1 month before analysis.

\section{Powdered samples characterizations}

Sample characterizations were obtained on finely ground powders after drying for about 1 month in air.

\section{NMR experiments}

High-resolution solid-state nuclear magnetic resonance (NMR) spectra $\left({ }^{1} \mathrm{H},{ }^{13} \mathrm{C}\right.$, and $\left.{ }^{29} \mathrm{Si}\right)$ were recorded on ASX 300 Bruker (Karlsruhe, Germany). Experimental conditions that we used for the different techniques are as follows. ${ }^{1} \mathrm{H}$ magic angle spinning (MAS): $4 \mu \mathrm{s}$ pulse length, recycling delay $10 \mathrm{~s}$, spinning frequency of $10 \mathrm{kHz}$, and 32 scans accumulation. ${ }^{13} \mathrm{C}$ CP-MAS (cross-polarization, magic angle spinning): $7 \mathrm{~mm}$ rotor at $4 \mathrm{kHz}$ spinning rate, $4 \mu \mathrm{s}$ pulse length for the proton, contact time $3 \mathrm{~ms}$ typically, and recycling delay

TABLE I

Starting Compositions DH/TH and Gelation Time of Gels in EtOH

\begin{tabular}{ccc}
\hline $\begin{array}{c}\text { Composition DH/ } \\
\mathrm{TH}(\mathrm{mol} \%)\end{array}$ & $\begin{array}{c}\text { Catalyst content }\left[\mathrm{CF}_{3} \mathrm{SO}_{3} \mathrm{H}\right] / \\
{[\mathrm{Si}](\mathrm{mol} / \mathrm{mol})(\%)}\end{array}$ & $\begin{array}{c}\text { Gelation } \\
\text { time } t_{\text {gel }}\end{array}$ \\
\hline $50 / 50$ & 0.05 & $1 \mathrm{~h} 15 \mathrm{~min}$ \\
$70 / 30$ & 0.05 & $3 \mathrm{~h}$ \\
$80 / 20$ & 0.1 & $5 \mathrm{~h}$ \\
$90 / 10$ & 0.3 & $\approx 18 \mathrm{~h}$ \\
$95 / 5$ & 0.3 & $\approx 18$ day \\
\hline
\end{tabular}

Molar ratio $[\mathrm{EtOH}] /[\mathrm{Si}]=1$ and hydrolysis ratio $h$ $=\left[\mathrm{H}_{2} \mathrm{O}\right] /[\mathrm{SiOEt}]=0.5$.

DH, Methyldiethoxysilane; TH, Triethoxysilane. 
10 s. ${ }^{29} \mathrm{Si}$ MAS: $4 \mu \mathrm{s}$ pulse, recycle delay of $120 \mathrm{~s}$, spinning frequency $5 \mathrm{kHz}$, with 500 scans. ${ }^{29} \mathrm{Si} \mathrm{CP}-\mathrm{MAS}$ technique: recycle delay $10 \mathrm{~s}, 4 \mu \mathrm{s}$ proton pulse length, contact time $3 \mathrm{~ms}$ typically, and spinning frequency 4 kHz. 2D ${ }^{29} \mathrm{Si}\left\{{ }^{1} \mathrm{H}\right\}$ heteronuclear correlation MAS: same conditions as for cross-polarization experiment.

\section{Thermogravimetric analysis}

Thermogravimetric analysis was performed using Hi-Res TGA Analyser (TA Instruments, New Castle, DE). TGA analyses were performed in a nitrogen atmosphere from ambient temperature to about $250^{\circ} \mathrm{C}$. Indeed, these gels have a good thermal and thermo-oxidative stability up to $\approx 300^{\circ} \mathrm{C}$, according to previous studies. ${ }^{2,9,10}$ About $5 \mathrm{mg}$ of the samples were heated in alumina crucible (Hi-Res sensitivity 1.0, ramp $30^{\circ} \mathrm{C} \mathrm{min}^{-1}$, resolution 4.0). Some of the experiments were carried out on a thermobalance, coupled with differential scanning analysis (DSC) with heating rate of $10^{\circ} \mathrm{C} \mathrm{min}^{-1}$, using SDT2960 simultaneous DSC-TGA (TA Instruments, New Castle, $\mathrm{DE})$. Investigations were done to quantify the oligomeric portion in gels due to evaporation of trapped volatile molecules after drying for 1 month at room temperature, and after thermal treatment using TGA analysis. The mass variations in gels are thus reported in Table II. The crude powders were first weighted after 1 month of air-drying to estimate the mass variation $\Delta m / m_{\text {theor, }}$ where $m_{\text {theor }}$ is the theoretical weight assuming that the formula of the repeat units is $\left[\mathrm{HSi}\left(\mathrm{CH}_{3}\right) \mathrm{O}_{2 / 2}\right]_{\alpha}\left[\mathrm{HSiO}_{3 / 2}\right]_{1-\alpha}$, where $\alpha$ is the molar ratio of the starting mixture $\mathrm{DH} / \mathrm{TH}$. TGA analysis was then performed to estimate the mass variation after thermal treatment $\Delta m / m^{\text {TGA }}$. We thus calculate an estimation of the total mass of trapped volatile molecules $\Delta m / m^{\text {tot }}$ by sum of $\Delta m / m_{\text {theor }}$ and $\Delta m / m^{\text {TGA }}$ (Table II). The mass variation $\Delta m / m_{\text {theor }}$ indicates an evaporation of free volatile species at room temperature for almost all gels from 50/50 to $95 / 5$. The TGA data recorded between 20 and $250^{\circ} \mathrm{C}$ showed only one weight loss $\Delta m / m^{\text {TGA }}$ with a sharp jump centered at about $75^{\circ} \mathrm{C}$, which may be associated to the evaporation of free volatile molecules, which are not completely released at room temperature. This was confirmed by an endothermic behavior in TGA coupled with differential thermal analysis. Moreover, we can exclude the presence of molecular $\mathrm{H}_{2} \mathrm{O}$ or EtOH (see discussion under Solid State NMR Spectroscopy section). After curing the gels at $100^{\circ} \mathrm{C}$ under air (or under vacuum), these volatiles are easy released, which results in a flat TGA curve up to $250^{\circ} \mathrm{C}$.

\section{FTIR spectroscopy}

IR spectra were recorded on powdered sample with the dried $\mathrm{KBr}$ pellet technique, using a Nicolet 710 (Thermo Optek, Madison, WI) FTIR spectrometer with 64 scans $\left(4 \mathrm{~cm}^{-1}\right.$ resolution) in the $4000-400 \mathrm{~cm}^{-1}$ range with background spectrum recorded in air.

\section{Kinetics of the starting sols}

${ }^{29}$ Si liquid NMR spectra were acquired on a Bruker Avance (250 MHz, Karlsruhe, Germany) spectrometer operating at $49.7 \mathrm{MHz}$ with proton decoupling. Recycle delays of $10 \mathrm{~s}$ were used to obtain quantitative results. The sols were prepared in the same conditions as described for powders in Table I in ordinary 10mm NMR tube with an internal 5-mm tube containing DMSO- $\mathrm{d}^{6}$ as locking solvent. The reference for chemical shift was tetramethylsilane. Twenty milligram of chromium(III) acetylacetonate $\left[\mathrm{Cr}(\mathrm{acac})_{3}\right]$ (Aldrich, Steinheim, Germany) was dissolved in the mixture as relaxation reagent. ${ }^{11}$ Acquisition spectra began within 2 or 3 min after injection of water. For aging times less than $1 \mathrm{~h}, 16$ scans were first accumulated, which corresponds to a time of $5 \mathrm{~min}$ per spectrum, and 256 scans were then run for time higher than $1 \mathrm{~h}$. To estimate the degree of polycondensation $(c)$, the following definition has been used:

$$
c=\sum_{i} \frac{i q_{i}}{f}
$$

TABLE II

Mass Variations in Gels as a Function of Their Composition

\begin{tabular}{cccc}
\hline Composition DH/TH $(\mathrm{mol} \%)$ & $\Delta m / m_{\text {theor }}(\%)^{\mathrm{a}}$ & $\Delta m / m^{\mathrm{TGA}}(\%)^{\mathrm{b}}$ & $\Delta m / m^{\text {tot }}(\%)^{\mathrm{c}}$ \\
\hline $50 / 50$ & $\approx 0$ & 0.1 & 0.1 \\
$70 / 30$ & 3.1 & 0.2 & 3.3 \\
$80 / 20$ & 5.5 & 1.0 & 6.5 \\
$90 / 10$ & 7.2 & 7.0 & 14.2 \\
$95 / 5$ & 10.8 & 9.6 & 20.4 \\
\hline
\end{tabular}

a $\Delta m / m_{\text {theor, }}$ Mass variation of gels dried in air for 1 month to the theoretical weight $m_{\text {theor }}$ assuming that the formula of the repeat units is $\left[\mathrm{HSi}\left(\mathrm{CH}_{3}\right) \mathrm{O}_{2 / 2}\right]_{\alpha}\left[\mathrm{HSiO}_{3 / 2}\right]_{1-\alpha \text {, }}$ where $\alpha$ is the molar ratio of the starting mixture $\mathrm{DH} / \mathrm{TH}$.

${ }^{\mathrm{b}} \Delta m / m^{\mathrm{TGA}}$, Measured from TGA data recorded for the air-dried gels after 1 month.

c $\Delta m / m^{\text {tot }}$, Sum of the first and second column. 
$q_{i}$ is the relative concentration of the various silicon sites ( $i$ indicates the number of oxo-bridges) and $f$ is the functionality of the monomer $(f=2$ for $\mathrm{DH}$ and $f=$ 3 for TH). This permits us to independently follow the aging of the sols before their use in the dip-coated thin-film fabrication.

\section{Thin-films preparation}

The coating procedure of the various samples was performed in ambient conditions, using a DM201 automatic dip-coater (Chemat Technology, Northridge, CA). For all samples, silicon wafers were first cleaned and activated to properly anchor the final thin-film by covalent $\mathrm{Si}-\mathrm{O}-\mathrm{Si}$ linkage using the following procedure: The silica surfaces of the wafer were degreased by sonication for $3 \mathrm{~min}$ by successive immersion in chloroform and ethanol. The samples were then dried in a stream of nitrogen, cleaned for $30 \mathrm{~min}$ in a hot $\left(90^{\circ} \mathrm{C}\right) \mathrm{H}_{2} \mathrm{SO}_{4} / \mathrm{H}_{2} \mathrm{O}_{2}(70 / 30 \mathrm{v} / \mathrm{v})$ solution ("piranha" solution), and then allowed to cool down to room temperature (over $30 \mathrm{~min}$ ). Caution! Piranha solution should be handled with extreme care. The clean substrates were then rinsed extensively with high-purity water, dried in a stream of nitrogen, and heated at $110^{\circ} \mathrm{C}$ in a clean oven for 20 $\mathrm{min}$. In the second step, sols of various compositions $\mathrm{DH} / \mathrm{TH}$ were synthesized in the similar conditions as described for powders in Table I. Before deposition, the resulting clear sols were let aging $\left(t / t_{\text {gel }}\right.$ $<1$ ), under magnetic stirring. The final concentration $C$ of the sols was finally adjusted by addition of $\mathrm{EtOH}$ to control the thickness of the film as a consequence of various sols viscosity. The freshly cleaned substrates were dipped for $1 \mathrm{~min}$ in the sols before withdrawing. The withdrawal speed $U$ of the apparatus can be adjusted in the range of $0.1-10 \mathrm{in} . / \mathrm{min}$ $(0.25-25 \mathrm{~cm} / \mathrm{min})$ to control the thickness. ${ }^{12,13}$ This results in thin-films of various thicknesses, in the range of nanometer to micrometer as measured either by ellipsometry or by infrared spectroscopy. The effect of further curing or solvent washing on the film thickness will be discussed in this study. Samples synthesized from 50/50, 70/30, 90/10, and 95/5 DH/ TH sols were respectively, denoted PMHS50, PMHS70, PMHS90, and PMHS95.

\section{Surface characterization}

Ellipsometry measurements

Film thickness $(e)$ and refractive index $(n)$ measurements were performed on a Plasmos SD 2300 ellipsometer (München, Germany) equipped with a 632.8 $\mathrm{nm}$ He-Ne laser with a spot size of $2 \mathrm{~mm}$. The angle of incidence was $70.0^{\circ}$, the incidence plane being perpendicular to the dip-coating withdrawal direc- tion to keep a good spatial resolution in the thickness gradient direction (see below). The thickness of the silicon oxide layer of about $2 \mathrm{~nm}$ was measured separately assuming the following indices of refraction: for $\mathrm{SiO}_{2}, n=1.457$; for $\mathrm{Si}, n=3.871-0.016 i{ }^{14}$ For coatings with thickness in the range of $30-150$ $\mathrm{nm}$, the values of $e$ and $n$ were calculated assuming that silica layer thickness is $2 \mathrm{~nm}$ and by postulating a bilayer structure, using standard models for optically isotropic medium. The calculated value of $n$ does not significantly vary with the thickness, which validates the model in that range of thickness. For the various compositions $\mathrm{DH} / \mathrm{TH}$ from PMHS95 to PMHS50, the values of $n$ were found in the range of $1.40 \pm 0.02$. For ultra-thin films (thickness less than $30 \mathrm{~nm}$ ), we assumed a constant refractive index of 1.40 for the organic film.

\section{FTIR spectroscopy}

IR absorption spectra were recorded on thin film, using a Nicolet 710 (Thermo Optek, Madison, WI) FTIR spectrometer. For each spectrum, 64 scans were recorded with $4 \mathrm{~cm}^{-1}$ resolution in the $4000-400 \mathrm{~cm}^{-1}$ range. A background spectrum was recorded using an unmodified silicon wafer in air. The change of the absorbance of the $\mathrm{Si}-\mathrm{O}$ stretching band at $1100 \mathrm{~cm}^{-1}$ was used to estimate its thickness. Indeed, the samples were placed perpendicularly to the beam so that the recorded spectrum reflects the absorbance of the thin film of thickness $e$, assuming the IR absorption spectrum obeys the Beer-Lambert law:

$$
A=2 \alpha_{\mathrm{SiO}} e
$$

where $A$ is the peak absorbance of the layer at $1100 \mathrm{~cm}^{-1}, \alpha_{\mathrm{SiO}}$ the absorption coefficient of $\mathrm{Si}-\mathrm{O}$ band, and the factor of 2 takes into account the presence of dip-coated films on both sides of the wafer. The value of the absorption coefficient $\alpha_{\mathrm{SiO}}$ has been calibrated for various thin film compositions from the peak absorbance of a 200-nm thick sample for which independent thickness could easily be measured using ellipsometry (Estimated accuracy of $\pm 5 \%$ ). The experimental values of $\alpha_{\mathrm{SiO}}$ decreased with the DH content (molar percentage) in the range of $50-95 \%$. This indicates a lower density of $\mathrm{Si}-\mathrm{O}$ vibration groups in low crosslinked gels as could be expected. Using calibration of FTIR peak for thin films, thicknesses of any mixture of $\mathrm{DH} / \mathrm{TH}$ can thus be measured easily.

\section{Contact angle measurements}

Contact angles with water were measured with a Kruss instrument (Hamburg, Germany) by applying droplet 


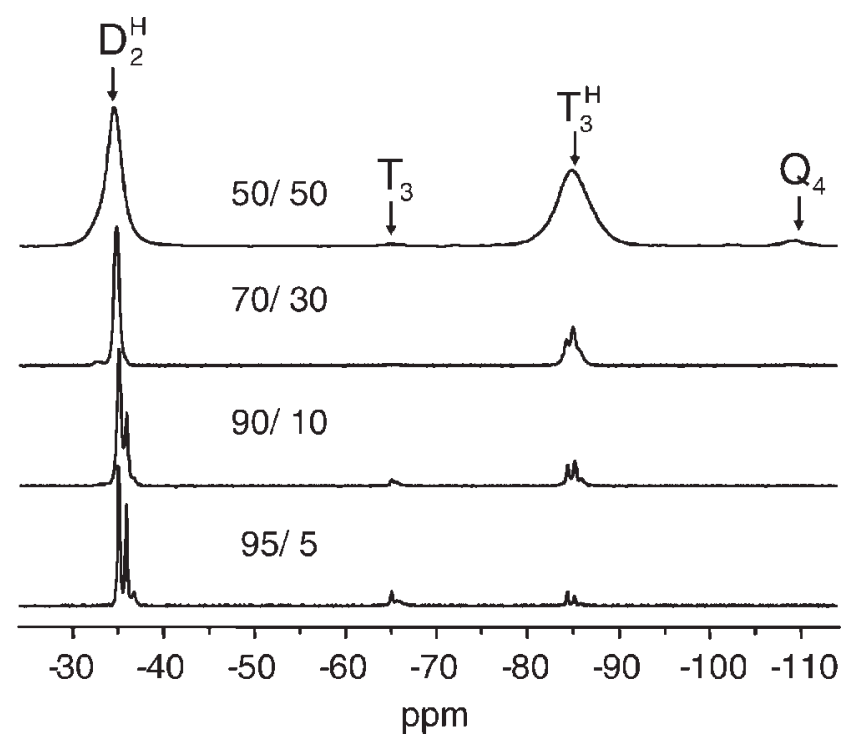

Figure $1{ }^{29} \mathrm{Si}$ CP-MAS NMR spectra with proton decoupling of the powdered gels as a function of the $\mathrm{DH} / \mathrm{TH}$ composition: 50/50, 70/30, 90/10, and 95/5 (mol \%) (see also Table II).

of water of 3-4 mm diameter radius to the surface. The contact angle was calculated using computerized image analysis. The contact angle value was then averaged over different samples with a good reproducibility $\left( \pm 1^{\circ}\right)$.

\section{Atomic force microscopy}

A V-shaped silicon nitride cantilever was used with a normal spring constant of about $0.1 \mathrm{~N} / \mathrm{m}$. Lateral stiffness of the contact is evaluated by recording the torsion signal (friction signal) while scanning over a very low size $(2 \mathrm{~nm}) .{ }^{15}$ Such a small scan size assures that the tip does not slide over the surface but remains in a static friction response. On the tested samples, the lateral force versus lateral displacement cycles are closed, indicating a purely elastic response of the samples. It will be experimentally shown that the contact stiffness is negligible as compared to the cantilever torsional spring constant. Then, the slope of these curves is proportional to the contact stiffness. ${ }^{15}$ No attempt was made to quantitatively interpret the results, because we were primarily interested in the qualitative behavior of the different samples. All the presented experiments were performed with a unique cantilever.

\section{RESULTS AND DISCUSSION}

\section{Powders characterization}

Powders characterization was performed to show that $3 \mathrm{D}$ gels are homogeneous and fully crosslinked. For this purpose, various multinuclear NMR techniques $\left({ }^{1} \mathrm{H},{ }^{13} \mathrm{C}\right.$, and $\left.{ }^{29} \mathrm{Si}\right)$ and FTIR spectroscopy were used to characterize samples with $\mathrm{DH} / \mathrm{TH}$ composi- tions ranging from 50/50 to $95 / 5$. The effects of curing the powders were also discussed.

\section{Solid state NMR spectroscopy}

In agreement with previous studies, ${ }^{1,4}$ all NMR data (Figs. 1 and 2) confirm that the $\mathrm{DH} / \mathrm{TH}$ siloxane network obtained in these gels have a high degree of polycondensation. No uncondensed $\mathrm{Si}-\mathrm{OEt}$ or $\mathrm{Si}-\mathrm{OH}$ species were found. The difunctional $(\mathrm{DH})$ and trifunctional $(\mathrm{TH})$ alkoxide monomers reacted thus totally. The obtained gels are characterized with two main fully condensed silicon subunits $\mathrm{SiH}$ $\left(\mathrm{CH}_{3}\right) \mathrm{O}_{2 / 2}$ and $\mathrm{SiHO}_{3 / 2}$, noted $\mathrm{D}_{2}^{\mathrm{H}}$ and $\mathrm{T}_{3}^{\mathrm{H}}$ throughout this study, according to the conventional nomenclature used in silicone chemistry. ${ }^{*}$ The ${ }^{29} \mathrm{Si}$ CP-MAS NMR spectra of the air-dried gels show two main complex signals in the range of resonance of the silicon subunits $\mathrm{D}_{2}^{\mathrm{H}}$ and $\mathrm{T}_{3}^{\mathrm{H}}$, respectively (Fig. 1). The ${ }^{1} \mathrm{H}$ MAS NMR spectra exhibited two lines located in the $\mathrm{SiH}$ resonance region at 4.2 and $4.6 \mathrm{ppm}$ due to $\mathrm{SiH}$ in $\mathrm{D}_{2}^{\mathrm{H}}$ and $\mathrm{T}_{3}^{\mathrm{H}}$ units, respectively (Fig. 2); the area of the two $\mathrm{SiH}$ peaks changes in agreement with the starting stoichiometry of $\mathrm{DH} / \mathrm{TH}$ mixtures. As expected, one peak attributed to the methyl proton $\mathrm{SiCH}_{3}$ of the $\mathrm{D}_{2}^{\mathrm{H}}$ units is also found at $0.05 \mathrm{ppm}$ for these gels. ${ }^{11}$ As mentioned previously, ${ }^{1,4}$ partial cleavage of $\mathrm{Si}-\mathrm{H}$ bonds of $\mathrm{DH}$ and $\mathrm{TH}$ units occurred in these gels. On the ${ }^{29} \mathrm{Si}$ NMR spectra, two minor peaks are detected in these gels corresponding to the fully condensed $\mathrm{Si}\left(\mathrm{CH}_{3}\right) \mathrm{O}_{3 / 2}\left(\mathrm{~T}_{3}\right)$ and $\mathrm{SiO}_{4 / 2}$ $\left(\mathrm{Q}_{4}\right)$ silicon units (Fig. 1), derived from partial cleavage of $\mathrm{Si}-\mathrm{H}$ bonds of $\mathrm{DH}$ and $\mathrm{TH}$ monomers, respectively. ${ }^{\dagger}$ This phenomena occurs during hydrolysis and condensation reaction as shown using liquid ${ }^{29} \mathrm{Si}$ NMR (see also next section). Nevertheless, the percentage of the total $\mathrm{Si}-\mathrm{H}$ bonds in the final gel network is more than $90 \%$ of the total amount of silicon as expected from the acidic conditions chosen for the syntheses, which minimize the cleavage of the $\mathrm{Si}-\mathrm{H}$ bond. ${ }^{2,5}$ The content of the various fully condensed silicon $\mathrm{D}_{2}^{\mathrm{H}}, \mathrm{T}_{3}, \mathrm{~T}_{3}^{\mathrm{H}}$, and $\mathrm{Q}_{4}$ subunits are estimated from integration of NMR ${ }^{29} \mathrm{Si}$ MAS spectra (Table III). For the soft gel systems (such as $90 / 10$ or

\footnotetext{
*In our adopted description of the Si site, the silicon units are designated by capital letters $\mathrm{D}, \mathrm{T}$, or $\mathrm{Q}$ indicating the functionality of the silicon site according to the conventional nomenclature used in silicone chemistry ${ }^{11}$ : A superscript will be added to refer to the type of functional groups bonded to the silicon atom (e.g. $\mathrm{H}, \mathrm{OH}$ or $\mathrm{H}, \mathrm{OEt}$ or $\mathrm{H})$; by convention, the methyl group are always omitted. Cyclic siloxane bearing $\mathrm{Si}-\mathrm{H}$ units are designed as $\mathrm{D}_{n}^{\mathrm{H}}$.

${ }^{\dagger}$ In no-decoupling ${ }^{29} \mathrm{Si}$ NMR MAS experiments, both $\mathrm{D}_{2}^{\mathrm{H}}$ and $\mathrm{T}_{3}^{\mathrm{H}}$ peaks exhibit as expected a doublet associated with a strong ${ }^{1} \mathrm{~J}\left({ }^{29} \mathrm{Si}-\mathrm{H}\right)$ coupling $(313$ and $294 \mathrm{~Hz}$, respectively), while no splitting of the $\mathrm{T}_{3}$ and $\mathrm{Q}_{4}$ peaks is observed.
} 


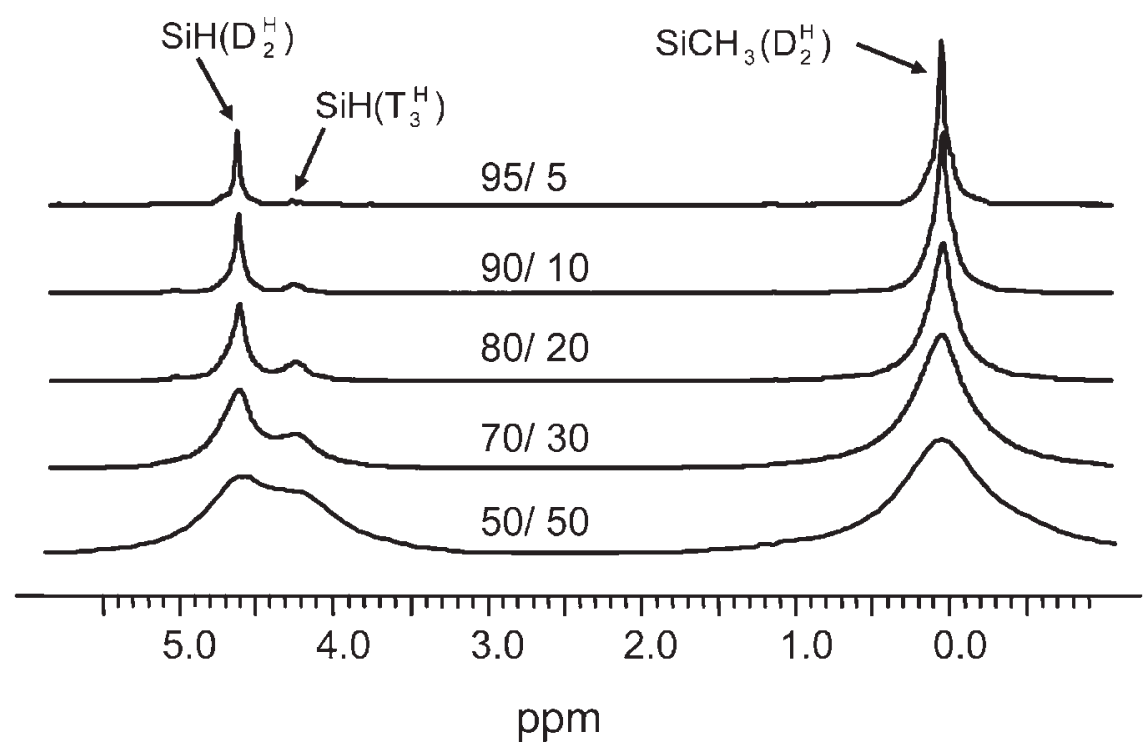

Figure $2{ }^{1} \mathrm{H}$ MAS NMR spectra of the air-dried powdered gels as a function of the DH/TH composition: 50/50, 70/30, 80/20, 90/10, and 95/5 (mol \%).

95/5), the crosslinked network can thus be described as a fully condensed polymer formed by PMHS chains $\mathrm{D}_{2}^{\mathrm{H}}$ interconnected by randomly dispersed $\mathrm{T}_{3}^{\mathrm{H}}$ (and $T_{3}$ ) subunits. Oligomeric silsesquioxanes such as $\mathrm{T}_{8}^{\mathrm{H}}$ species ${ }^{16}$ are not detected in NMR spectra (as in FTIR). No resonance is detected on the ${ }^{29} \mathrm{Si}$ NMR spectra for $\mathrm{Si}-\mathrm{OH}$ or $\mathrm{Si}-\mathrm{OEt}$ species based on $\mathrm{TH}$ and DH subunits such as PMHS chain-ends $\left(D_{1}^{\mathrm{H}}\right)$ or crosslinked species of $\mathrm{TH}$ subunits bearing $\mathrm{Si}-\mathrm{OH}$ or $\mathrm{Si}-\mathrm{OEt}$ groups $\left(\mathrm{T}_{1}^{\mathrm{H}}, \mathrm{T}_{2}^{\mathrm{H}}\right) .{ }^{1} \mathrm{H}$ NMR confirmed that ethoxy groups $\mathrm{Si}-\mathrm{OEt}$ or silanol $\mathrm{Si}-\mathrm{OH}$ are absent in the air-dried gels and that no solvent molecule was detected such as $\mathrm{EtOH}$ and $\mathrm{H}_{2} \mathrm{O}$. Finally, the ${ }^{13} \mathrm{C}$ NMR spectra (not shown ${ }^{\S}$ ) of the $50 / 50$ and 90/10 air-dried gels confirmed that $\mathrm{Si}-\mathrm{OEt}$ or $\mathrm{EtOH}$ are absent. Similar conclusions are obtained from FTIR spectroscopy of the gels (see next section). The absence of any residual silanol (or $\mathrm{Si}-\mathrm{OEt}$ ) and the formation of a fully condensed network is thus clearly shown.

The mobility of the various silicon units is correlated with the degree of crosslinking of the gel network (or the $\mathrm{TH} / \mathrm{DH}$ ratio), which results in pro-

\footnotetext{
${ }^{5}$ The ${ }^{29} \mathrm{Si}$ NMR signal of partially condensed species derived from $\mathrm{DH}$ and $\mathrm{TH}$ monomer can be easily distinguished, if present, in three distinct regions ${ }^{11}: \mathrm{T}_{2}^{\mathrm{H}}(\delta \approx-75$ ppm); $\mathrm{T}_{1}^{\mathrm{H}}(\delta \approx-65 \mathrm{ppm}) ; \mathrm{D}_{1}^{\mathrm{H}}(\delta \approx-25 \mathrm{ppm})$.

${ }^{5}$ In ${ }^{13} \mathrm{C}$ CP-MAS spectra, the main resonance corresponding to the methyl group of $\mathrm{DH}$ subunits $\mathrm{SiH}\left(\mathrm{CH}_{3}\right) \mathrm{O}_{2 / 2}$ is found as expected at $0.8 \mathrm{ppm}$. No resonance was observed at $\approx 60$ and at $\approx 20 \mathrm{ppm}$, which excludes respectively $\mathrm{CH}_{3}$ and $\mathrm{CH}_{2}$ arising from ethoxy group. For the 90/10 gel (but not for the 50/50 gel), a minor peak is observed at -3 ppm but its area is less than $5 \%$ of the total. It is attributed to $\mathrm{Si}\left(\mathrm{CH}_{3}\right) \mathrm{O}_{3 / 2}$ subunits arising from a partial cleavage of the $\mathrm{SiH}$ group of the $\mathrm{DH}$ precursor.
}

gressive sharpening of both ${ }^{29} \mathrm{Si}$ and ${ }^{1} \mathrm{H}$ NMR spectra (see Figs. 1 and 2). More precisely, for the ${ }^{29} \mathrm{Si}$ NMR spectra, the linewidth of peaks due to $\mathrm{D}_{2}^{\mathrm{H}}$ and $\mathrm{T}_{3}^{\mathrm{H}}$ units decreases with gel composition from $50 / 50$ to $95 / 5$ (Fig. 1). The same effect can be seen in Figure 2 for both ${ }^{1} \mathrm{H}$ NMR resonance of $\mathrm{SiH}(\mathrm{DH})$ and $\mathrm{SiH}(\mathrm{TH})$. This indicates the formation of homogeneous systems without strong phase separation. Indeed, if phase separation had occurred in a large extent between cluster of self-condensed TH network and PMHS polymer, the resonance of $\mathrm{T}_{3}^{\mathrm{H}}$ or $\mathrm{SiH}$ (TH) would have been broader than the $\mathrm{DH}$ resonance. A second argument in favor of the homogeneous structural model is given by the presence of complex fine structures in ${ }^{1} \mathrm{H}$ and ${ }^{29} \mathrm{Si}$ NMR spectra for the soft gel systems, such as $90 / 10$ or $95 / 5$, as a consequence of linewidth sharpening. This indicates the presence of cocondensed $\mathrm{DH}$ and $\mathrm{TH}$ species having different chemical shifts. For instance, a splitting pattern appears for $\mathrm{T}_{3}^{\mathrm{H}}$ signal in the ${ }^{29} \mathrm{Si}$ spectra of $95 / 5$ and $90 / 10$ gels (Fig. 1), while two peaks are clearly seen for $\mathrm{D}_{2}^{\mathrm{H}}$ (see also data list of peaks in Table III). To confirm the presence of cocondensed species, the structural proximity of the $\mathrm{DH}$ and $\mathrm{TH}$ units has been investigated using two dimensional ${ }^{29} \mathrm{Si}\left\{{ }^{1} \mathrm{H}\right\}$ heteronuclear correlation MAS spectroscopy $^{17}$ on the three samples 50/50, 90/10, and $95 / 5$ (not shown here). The 2D-NMR correlation charts of $\mathrm{Si}-\mathrm{CH}_{3}\left(\delta^{\mathrm{H}}=0.05 \mathrm{ppm}\right)$ and $\mathrm{T}_{3}^{\mathrm{H}}\left(\delta^{\mathrm{Si}}=-85 \mathrm{ppm}\right)$ signals are correlated in all gels showing the structural proximity of $\mathrm{TH}$ and $\mathrm{DH}$. To conclude, all NMR data agree with the structural model of the final DH/TH gel in which fully cocondensed difunctional and trifunctional units are highly dispersed, yielding a highly homogeneous material. 
TABLE III

The Various Silicon Sites Present in 95/5, 90/10, and 50/50 (mol \%) Gels and Their Relative Proportions from Quantitative ${ }^{29} \mathrm{Si}$ MAS Analysis

\begin{tabular}{|c|c|c|c|c|c|c|c|c|}
\hline \multirow[b]{2}{*}{$\underline{\mathrm{DH}} / \mathrm{TH}^{\mathrm{a}}$} & \multicolumn{2}{|c|}{$\mathrm{D}_{2}^{\mathrm{H}}$} & \multicolumn{2}{|c|}{$\mathrm{T}_{3}$} & \multicolumn{2}{|c|}{$\mathrm{T}_{3}^{\mathrm{H}}$} & \multicolumn{2}{|c|}{$\mathrm{Q}_{4}$} \\
\hline & $\delta^{\mathrm{b}}$ & $\%$ & $\delta$ & $\%$ & $\delta$ & $\%$ & $\delta$ & $\%$ \\
\hline $50 / 50$ & -34.7 & 46.3 & -65.2 & 1.5 & -84.8 & 48.3 & -109.4 & 3.9 \\
\hline $90 / 10$ & $\begin{array}{l}-35.1 \\
-36.0 \\
-36.9\end{array}$ & 79.9 & -65.1 & 8.2 & $\begin{array}{l}-84.4 \\
-85.2 \\
-85.9\end{array}$ & 10.9 & Not obs. & \\
\hline $95 / 5$ & $\begin{array}{l}-35.1 \\
-36.0 \\
-36.9\end{array}$ & 83.6 & -65.0 & 10.0 & $\begin{array}{l}-84.4 \\
-85.1 \\
-85.9\end{array}$ & 5.9 & Not obs. & \\
\hline
\end{tabular}

${ }^{\text {a }}$ From integration of NMR spectra, the ratios between the area of the resonance of $\mathrm{DH}$-derived subunits $\left(\mathrm{D}_{2}^{\mathrm{H}}\right.$ and $\left.\mathrm{T}_{3}\right)$ and of $\mathrm{TH}$-derived subunits $\left(\mathrm{T}_{3}^{\mathrm{H}}\right.$ and $\left.\mathrm{Q}_{4}\right)$ are in good agreement with the starting stoichiometry of $\mathrm{DH} / \mathrm{TH}$ sol-gel mixtures.

${ }^{\mathrm{b}}$ We noticed a very small broad peak (less than $1 \%$ of the total) at $\delta \approx-33 \mathrm{ppm}$ in the $90 / 10$ and $95 / 5$ gels, which is attributed to $\mathrm{D}_{2}^{\mathrm{H}}$ subunits in cocyclic $\mathrm{DH} / \mathrm{TH}$ species $(n=4)$ by reference to 1,3,5,7-tetramethylcyclosiloxane $\left(\mathrm{D}_{4}^{\mathrm{H}}\right)$ for which the ring strain $(n=4)$ deshielded the ${ }^{29} \mathrm{Si}$ nucleus resulting in chemical shifts of higher frequency than the main resonance for PMHS chain at $\delta \approx-35 \mathrm{ppm}$.

Finally, it is worth noticing that curing does not induce major change in the NMR spectra and FTIR spectra. For instance, ${ }^{29} \mathrm{Si}$ NMR spectra showed no marked differences after moderate thermal treatment at $100^{\circ} \mathrm{C}$ for all gels from $95 / 5$ to $50 / 50$. Indeed, the ratio between resonance corresponding to $\mathrm{DH}$ and $\mathrm{TH}$ units remains quasi unchanged, the linewidth of the peaks are not noticeably modified, and the content of the various silicon sites presented in Table III do not vary significantly upon aging or thermal treatment of the gels. As observed in ${ }^{29} \mathrm{Si}$ NMR experiments, curing does not induce major change in the ${ }^{13} \mathrm{C}$ or ${ }^{1} \mathrm{H}$ MAS NMR spectra. Thus, these materials present no spectral evolution and a good chemical stability during drying or thermal aging at moderate temperature, because they are fully crosslinked with no uncondensed SiOEt or $\mathrm{SiOH}$ species.

However, curing of the gel can fundamentally change the properties of the material because the oligomeric portion trapped in the network could act as plasticizer in mechanical properties for instance. To estimate the content of some trapped oligomeric volatiles species, the mass variations of gels have been measured as a function of their composition after thermal treatment (see Experimental part and Table II). It is worth noticing that the higher the degree of crosslinking, the lower is their content in the polymeric network, because their formation is less statistically favored. For the lower crosslinked gels such as $90 / 10$ or $95 / 5$, curing can thus induce important mass variations and structural change due to the evaporation of trapped oligomeric species. In a better approach, works are in progress to determine the molecular weight of the oligomeric portion after solvent extraction.

\section{Infrared spectroscopy}

FTIR spectra are very similar to the one previously reported for 50/50, 70/30, and 91/9 gels. ${ }^{4}$ The spectra confirms the high content of $\mathrm{Si}-\mathrm{H}$ bonds in these gels. Two $\mathrm{Si}-\mathrm{H}$ bands are located at about 2250 and $2180 \mathrm{~cm}^{-1}$, respectively, due to $\mathrm{Si}-\mathrm{H}$ stretching in $\mathrm{TH}$ and $\mathrm{DH}$ units, and the variation of their relative intensities are in agreement with the composition of the gels. The bending band of $\mathrm{Si}-\mathrm{H}$ is found at about $835 \mathrm{~cm}^{-1} \cdot{ }^{11}$ FTIR spectra confirmed that these gels are fully crosslinked by a strong doublet located at about $1000-1100 \mathrm{~cm}^{-1}$ due to the asymmetric stretching of siloxane $\mathrm{Si}-\mathrm{O}-\mathrm{Si}$ bonds and by a flat spectra in the $v_{\mathrm{O}-\mathrm{H}}$ region $\left(2300-4000 \mathrm{~cm}^{-1}\right)$ due to the absence of hydroxyl group $\mathrm{Si}-\mathrm{OH}$.

\section{Study of the $90 / 10$ starting sol}

To investigate the reactivity of the precursors in the experimental conditions, a ${ }^{29} \mathrm{Si}$ liquid NMR study of the sol starting solution was performed. It also allowed to follow independently the aging of the sols before their use in the dip-coating experiment. Two solutions were hydrolyzed in the same conditions $\left(h=0.5 ;[\mathrm{EtOH}] /[\mathrm{Si}]=1 ;\left[\mathrm{CF}_{3} \mathrm{SO}_{3} \mathrm{H}\right] /[\mathrm{Si}]\right.$ $=0.3 \%$, a mixture containing $\mathrm{DH} / \mathrm{TH} 90 / 10$ and the DH precursor, which was mainly studied for simplification of signal assignment in ${ }^{29} \mathrm{Si}$ NMR. Spectra of a mixture DH/TH $90 / 10$ after $1 \mathrm{~h}$ of hydrolyzation are presented in Figure 3.

The assignments have been done by comparison with previous results ${ }^{4}$ where hydrolysis/condensation was done in the following conditions: $h=1$; $[\mathrm{EtOH}] /[\mathrm{Si}]=2 ; \mathrm{HCl} \mathrm{pH} \approx 6$. After $1 \mathrm{~h}$, the polycondensation of the DH precursor was mostly com- 


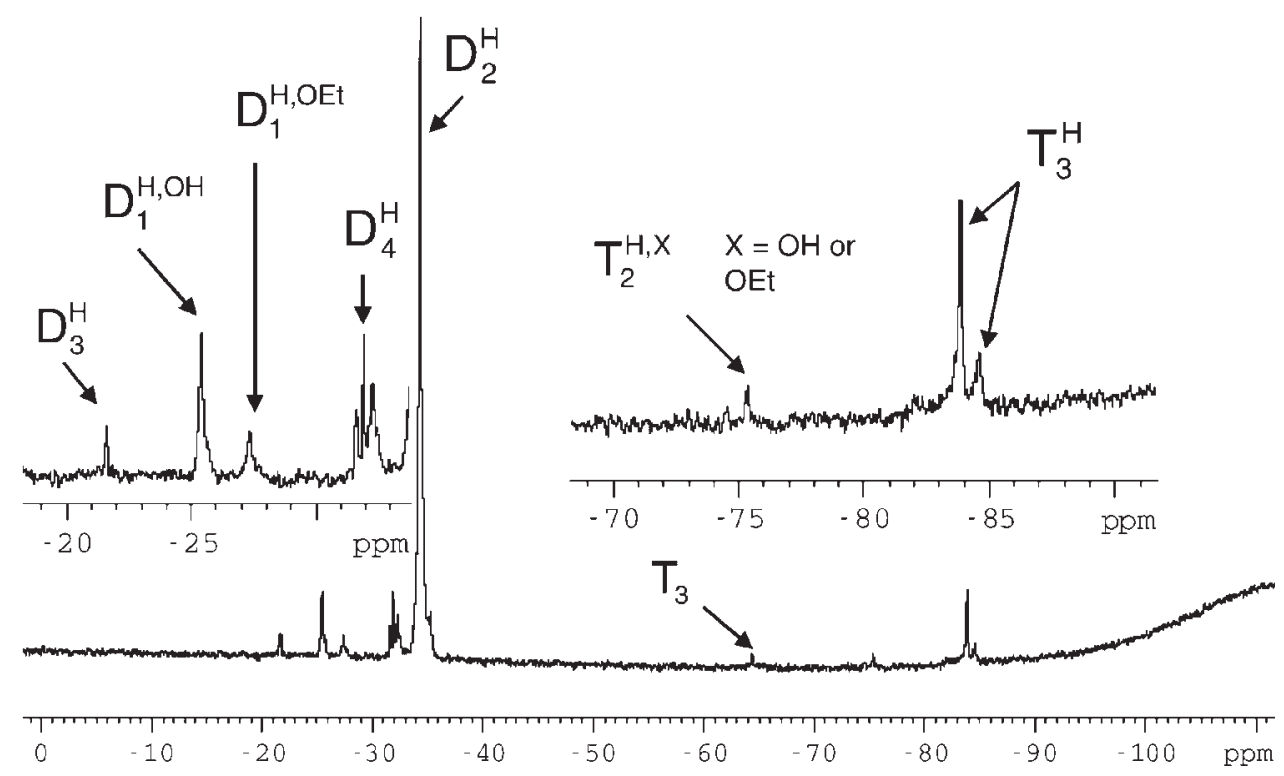

Figure $3{ }^{29} \mathrm{Si}$ NMR spectra on hydrolyzed solution of DH/TH 90/10 mixture $\left(h=0.5 ;[\mathrm{EtOH}] /[\mathrm{Si}]=1 ;\left[\mathrm{CF}_{3} \mathrm{SO}_{3} \mathrm{H}\right] /[\mathrm{Si}]\right.$ $=0.3 \%$ ) recorded after $1 \mathrm{~h}$.

pleted. The main signal at $-34.3 \mathrm{ppm}\left(\mathrm{D}_{2}^{\mathrm{H}}\right.$ : $73 \%$; normalized to $100 \%$ of the total amount of $\mathrm{DH}$ units) corresponds to fully condensed silicon involved in linear PHMS chains or in cyclic species $(n>4)$. A large proportion of silicon units involved in two small cyclic species $(n=3$ and 4$)$ was also detected respectively, at $-21.5\left(\mathrm{D}_{3}^{\mathrm{H}}: 2 \%\right)$ and at -31.9 (complex triplet) $\left(\mathrm{D}_{4}^{\mathrm{H}}: 15 \%\right)$. The complex NMR signal in this last region indicates, by comparison with spectra of DH system (not shown), the presence of cocyclic species $(n=4)$ that could overlap with self-condensed species. The other peaks at -25.4 and -27.3 were respectively, assigned to silanol and ethoxysiloxane chain-ends $\mathrm{D}_{1}^{\mathrm{H}, \mathrm{OH}}(8.5 \%)$ and $\mathrm{D}_{1}^{\mathrm{H}, \mathrm{OEt}}(1.5 \%)$ due to partial polycondensation. No other species were detected, indicating that the $\mathrm{DH}$ monomer was totally consumed. The spectrum presents similar features in the region corresponding to $\mathrm{TH}$ unit, indicating that the polycondensation of the $\mathrm{TH}$ precursor was mostly completed. The signal of fully condensed $\mathrm{T}_{3}^{\mathrm{H}}$ silicon clearly shows a doublet-like pattern at -84.5 and -83.7 due to various cocondensed species that are shifted to low field by comparison to self-condensation of TH units $(\delta=-85.3$ from Ref. 4). The presence of $\mathrm{T}_{3}^{H, X}(\mathrm{X}=\mathrm{OH}$ or OEt) silicon sites at $\delta=-75.3$ corresponding to doubly condensed species with one silanol (or ethoxide) group indicates partial polycondensation of TH unit, which is roughly estimated to $10 \%$ of the total amount of TH units normalized to $100 \%$. Lastly, a small signal $(<1 \%$ to the total number of silicon) at -64.5 is attributed to the partial cleavage of $\mathrm{SiH}$ groups of $\mathrm{DH}$ units leading ultimately to fully condensed $\mathrm{T}_{3}$ species.

The reactivity of the $\mathrm{DH} / \mathrm{TH}$ system can be measured as a function of time by calculating the degree of condensation (c), which represents the relative number of $\mathrm{Si}-\mathrm{O}$ bonds in condensed siloxane form over the number of SiOR residual bonds (see Experimental part). Within about less than $10 \mathrm{~min}$, which corresponds to the time to collect the first spectrum (see Experimental part), the value of the degree of condensation reached 0.96 for $\mathrm{DH}$ and 0.95 for $\mathrm{TH}$; no significant evolution of $c$ was detected from $10 \mathrm{~min}$ to $1 \mathrm{~h}$ and even until gelation occurs in the NMR tube after about $18 \mathrm{~h}$. This result confirms the very high reactivity of the $\mathrm{DH} / \mathrm{TH}$ system in our experimental condition. By comparison with previous results using $\mathrm{HCl}_{1}{ }^{1,4}$ it is clear that hydrolytic/condensation is faster using $\mathrm{CF}_{3} \mathrm{SO}_{3} \mathrm{H}$, due to its strong acidity. More precise examination of the spectra from 1 to $16 \mathrm{~h}$ before gelation showed, however, that the like- $\mathrm{D}_{4}^{\mathrm{H}}$ cyclic signal increased from 15 to $18 \%$ and that the silanol chain-ends $\mathrm{D}_{1}^{\mathrm{H}, \mathrm{OH}}$ decreased from 8.5 to $6 \%$, while the main signal $\mathrm{D}_{2}^{\mathrm{H}}$ was constant at $73 \%$. These most significant variations qualitatively indicate a growth of the polymeric precursors and a redistribution ${ }^{18}$ of oligomeric species with aging time.

To conclude, the $\mathrm{DH} / \mathrm{TH} 90 / 10 \mathrm{sol}$ is quasi totally polycondensed in less than $10 \mathrm{~min}$. The amount of silicon involved in small cyclic species $(n=3,4)$ in the $90 / 10$ mixture is quite high, because there are thermodynamically stable by-products. Because of their high volatility, it is clear that these species should be released in a large extent by evaporation in air after gelation (compare with Table II), but a minor part, such as mixed cocyclic species, could be covalently grafted in the polymeric network as shown by ${ }^{29} \mathrm{Si}$ solid state NMR (see note in Table III). The presence of uncondensed silicon sites with ethoxy 
TABLE IV

Typical Dip-Coated Thin-Films of Controllable Thickness and Ratio, Fabricated from Concentrated DH/TH Sols of About 4M Synthesized in Similar Conditions Described in Table I

\begin{tabular}{lccc}
\hline $\begin{array}{l}\text { Concentration of sols } \\
C(M)\end{array}$ & Aging time $t / t_{\text {gel }}$ & $\begin{array}{c}\text { Withdrawal speed } \\
U \text { (in./min) }\end{array}$ & $\begin{array}{c}\text { Thickness } \\
e(\mathrm{~nm})^{\mathrm{a}}\end{array}$ \\
\hline $\begin{array}{l}\text { PMHS90 thin film } \\
4.13\end{array}$ & 0.8 & 4.5 & 1400 \\
4.13 & 0.8 & 0.4 & 660 \\
4.13 & 0.5 & 0.8 & 265 \\
PMHS70 thin film & 0.85 & 0.4 & 230 \\
$\quad \begin{array}{l}4.02 \\
\text { PMHS50 thin film }\end{array}$ & 0.4 & 2 & 155 \\
3.91 & & & \\
\hline
\end{tabular}

${ }^{\text {a }}$ As measured using infrared spectroscopy (see Experimental part).

(SiOEt) or hydroxy $(\mathrm{SiOH})$ groups (about $10 \%$ of the total number of silicon) should favor the grafting of the film on silicon oxide surfaces bearing $\mathrm{SiOH}$ groups.

\section{Thin films preparation and characterization}

\section{Preparation}

Thin films with tunable crosslinked ratio $\mathrm{DH} / \mathrm{TH}$ and controlled thickness were synthesized using dip-coating procedure. Table IV shows typical thicknesses of homogeneous thin films obtained from various concentrated sols $(\approx 4 M)$ after aging of the $\mathrm{DH} /$ $\mathrm{TH}$ mixtures. The resulting films, with thicknesses ranging from 0.15 to $1.5 \mu \mathrm{m}$, presented a good optical homogeneity on most of the surface.

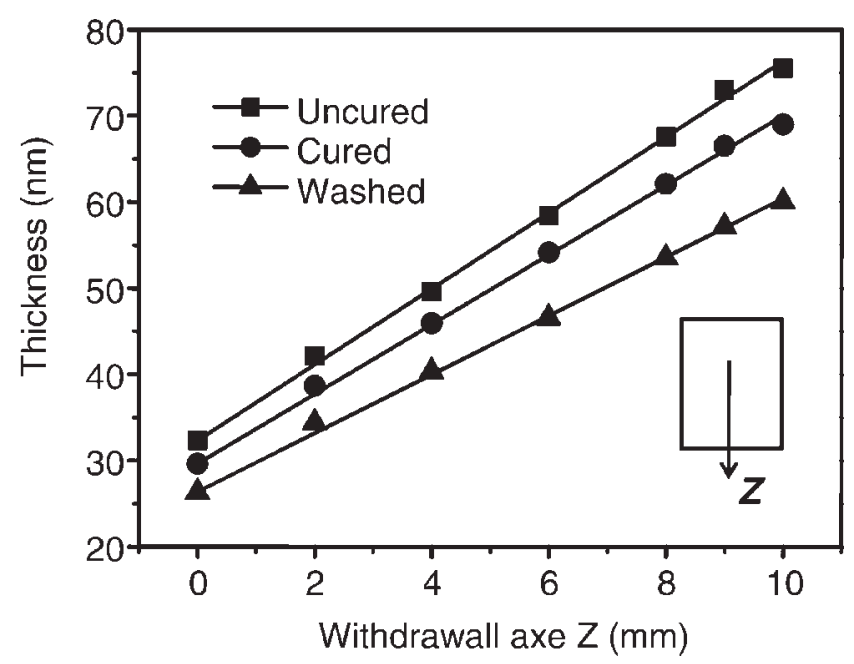

Figure 4 Typical dip-coated gradient-thickness thin-films from $\mathrm{DH} / \mathrm{TH} 90 / 10$ sols of $2.1 \mathrm{M}$ concentration as measured using ellipsometry (see also Fig. 5). The effect of thermal treatment and washing treatment on the thickness profile are shown by comparison with uncured film (cured in a vacuum ramp for $2 \mathrm{~h}$ at $100^{\circ} \mathrm{C}$ and washed in $\mathrm{CCl}_{4}$ at room temperature for $1 \mathrm{~h}$ ). Straight lines correspond to least square fit of the experimental data and are guide for the eyes; schematic view is also included.
Interestingly, when decreasing the concentration $C$ of the $90 / 10$ sol in the range of $2.5-0.5 M$, dip-coating procedure can produce thin films with gradientthickness as measured by ellipsometry (Figs. 4 and 5). Their mean thickness can be controlled in the nanometer range (at constant $t / t_{\text {gel }}$ value) as a consequence of different viscosity of the solution, and the gradient-thickness values are also strongly correlated with C (Fig. 5). For samples of about $100 \mathrm{~nm}$ thick, gradient-thickness produces a continuous change in color and brightness of light reflected from the filmsubstrate interface from brown to blue. The refractive index of 1.40 calculated using standard models in ellipsometry was constant over all the coverage with an accuracy of \pm 0.01 . The value is in good agreement with the refractive index of liquid oligomers of polymethylhydrosiloxane $[\mathrm{MeHSiO}]_{x}(n=1.396)$. This result indicates that dense films are produced, which is confirmed by their optical transparency and their low AFM roughness of 1-1.5 nm. The gradient

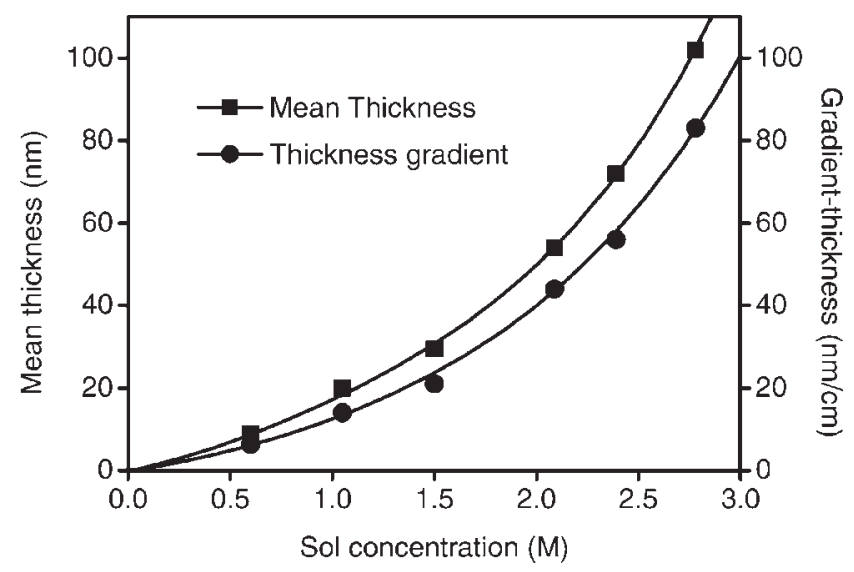

Figure 5 Thickness and gradient-thickness of uncured PMHS90 thin film as function of sol concentration as measured using ellipsometry. The sol DH/TH 90/10 was synthesized in similar conditions as described in Table I. The parameters $t / t_{\text {gel }}(0.05)$ and $U(0.25 \mathrm{~cm} / \mathrm{min})$ were constant for all samples. The lines are guides for the eyes. 


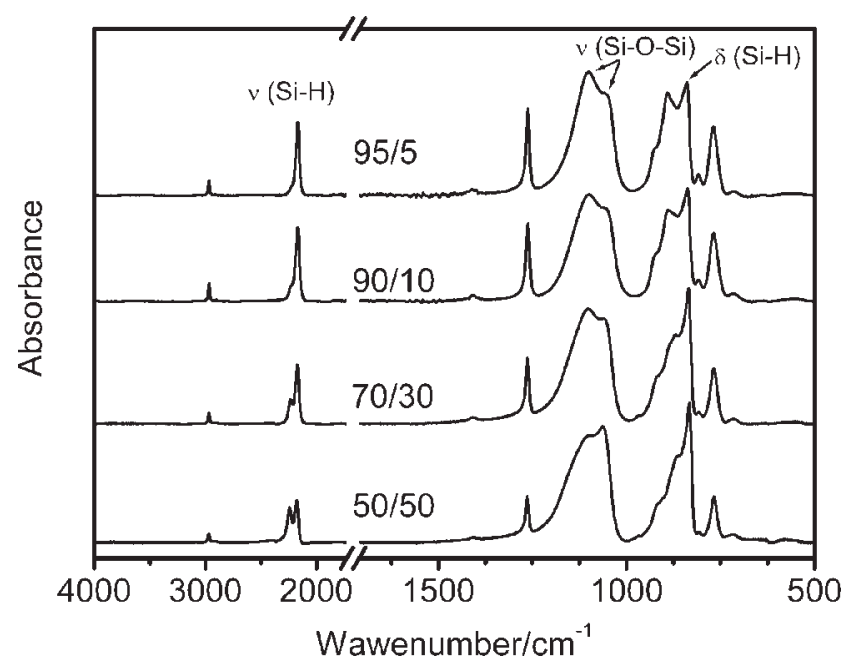

Figure 6 Infrared spectra of uncured thin-films as function of the DH/TH composition: 50/50, 70/30, 90/10, and 95/5 (mol \%).

thickness films were obtained with constant dipcoating speed. We believe that the variations of the evaporation rate, which leads to an increase of viscosity of the entrained film and the surface tension effects, can be responsible of the profile shape. We think that the design and the control of such gradient thickness thin-film may have potential applications in material science. ${ }^{19,20}$

\section{Characterization}

Immediately after preparation, infrared spectroscopy (Fig. 6) showed a flat spectrum in the $\mathrm{v}_{\mathrm{O}-\mathrm{H}}$ region of $2300-4000 \mathrm{~cm}^{-1}$, which indicates the absence of hydroxyl group in uncured thin films and the formation of fully crosslinked network. Spectra are similar to the one obtained on the corresponding powders. A strong doublet band located at $1000-1100 \mathrm{~cm}^{-1}$ corresponding to the asymmetric stretching of $\mathrm{Si}-\mathrm{O}-\mathrm{Si}$ bonds confirms that the polysiloxane network is fully condensed as shown by solid state NMR for powders. The absorbance of $\mathrm{Si}-\mathrm{H}$ bands of $\mathrm{TH}$ and $\mathrm{DH}$ units, at about 2250 and $2180 \mathrm{~cm}^{-1}$, indicates a high content of $\mathrm{Si}-\mathrm{H}$ in thin-films, and their relative intensities is modified in agreement with the composition of the starting $\mathrm{DH} / \mathrm{TH}$ sols. The bending band of $\mathrm{Si}-\mathrm{H}$ bonds ${ }^{11}$ is found at about $835 \mathrm{~cm}^{-1}$. Other bands have been attributed to the methyl group in $\mathrm{Si}-\mathrm{CH}_{3}$ of DH units at about $760\left(\delta_{r}\right.$ rocking mode), $1265\left(\delta_{s} \mathrm{CH}_{3}\right.$ symmetric deformation), $1405\left(\delta_{a} \mathrm{CH}_{3}\right.$ asymmetric deformation), and at $2970 \mathrm{~cm}^{-1}\left(v_{a} \mathrm{CH}_{3}\right.$ asymmetric stretching) by comparison with liquid oligomers of PMHS. ${ }^{11}$ The intensities of these methyl and $\mathrm{Si}-\mathrm{H}$ stretching bands of $\mathrm{DH}$ subunits both increase with the composition of the $\mathrm{DH}$ precursor.
In addition, the effect of curing and washing thin films is shown in Figure 4 as measured by ellipsometry. The thickness of the PMHS90 thin films decreased by about $10 \%$ after curing at $100^{\circ} \mathrm{C}$ and $30 \%$ after washing in $\mathrm{CCl}_{4}$ by comparison with uncured thin films. Qualitatively, FTIR measurements are in good agreement with ellipsometry, showing a decrease of the absorbance of the spectra. Moreover, the spectra do not change significantly, which indicates that the $\mathrm{Si}-\mathrm{H}$ bonds are preserved in the material, and that trapped species such as oligomeric or cyclic species have similar FTIR spectra as the network. These results are also confirmed by the mass of volatile species found in the corresponding 90/10 powders (see Table II). The extraction of trapped species in organic solvent is obviously more efficient than the thermal treatment because diffusion of $\mathrm{CCl}_{4}\left(\mathrm{CHCl}_{3}\right.$, toluene, or $n$-hexane for instance) leads to a significant swelling of the PMHS90 network. Solvation favors the departure of molecular species of higher molecular mass, which are not released at $100^{\circ} \mathrm{C}$ even under vacuum. This purification is necessary in further characterization of the properties of the material, because noncrosslinked molecular species in the network could act as plasticizer leading to disparities in mechanical properties for instance.

\section{Stability}

One advantage of the sol-gel process is that crosslinking and surface attachment can be simultaneously performed to anchor the final thin-film by covalent $\mathrm{Si}-\mathrm{O}-\mathrm{Si}$ linkages on the native silicon oxide $\mathrm{SiO}_{2}$ layer of the substrate. Indeed, the $\mathrm{SiO}_{2}$ layer was first treated with the "piranha" solution (see Experimental part) to remove all organic impurities and to increase the surface density of silanol groups before dip-coating. Under these conditions, about 5 $\times 10^{14}$ silanols groups per square centimeter are obtained on silica surface. ${ }^{21}$ The partial condensed silicon subunits of the mixed precursors in the 90/10 sol (10\%: mainly $\mathrm{Si}-\mathrm{OH}$ and some $\mathrm{Si}-\mathrm{OEt}$ groups as shown by liquid NMR) can then react presumably with surface $\mathrm{Si}-\mathrm{OH}$ groups of these so-treated $\mathrm{SiO}_{2}$ layer to lead to $\mathrm{Si}-\mathrm{O}-\mathrm{Si}$ linkages. The films are really surface-attached and chemically stable. For instance, the films could be immersed in $\mathrm{CCl}_{4}$ under reflux (1 day) or at room temperature (several months) without any noticeable effect: No modification of their thickness could be detected using ellipsometry. FTIR spectroscopy confirmed that the chemical structure of the film is preserved. After surface attachment and crosslinking, thin film cannot be removed from the surface even by rigorous extraction with boiling solvent. The covalent bonding of the film is a key point for the robustness of the surface coating. 
In the case of $\mathrm{Si}-\mathrm{H}$-substituted precursors, the reaction mechanism could include the surface-catalyzed cleavage of $\mathrm{SiH}$ groups with surface water ${ }^{22}$ followed by $\mathrm{Si}-\mathrm{O}-\mathrm{Si}$ linkages. Similar mechanisms of reaction with silica surface have been reported recently for poly(methylhydro-dimethyl)siloxane copolymers ${ }^{23}$ and for organosilicon hydrides $\mathrm{RSiH}_{3}{ }^{24}$ The structure and crosslinking of the film near the silica surface is thus probably different from the bulk and should be studied in detail.

By contrast, the films can be partially delaminated by immersing them in basic water $(\mathrm{pH}$ 12) at room temperature or in protic solvent such as $\mathrm{EtOH}$. This does not occur in neutral water. In basic medium, delamination could involve the breaking of $\mathrm{Si}-\mathrm{O}-\mathrm{Si}$ bonds at the silica surface. Moreover, under basic medium, we noticed the formation of hydrogen bubbles due to the cleavage of $\mathrm{SiH}$ group in $\mathrm{SiOH}^{2}$

Various curing treatment has been performed in air to evaluate the thermal stability of the PMHS90 films from examination of FTIR spectra. Minor differences were observed after curing under air at $150^{\circ} \mathrm{C}$ : The relative intensity of the SiOSi doublet at $1000-1100 \mathrm{~cm}^{-1}$ is slightly changed. These minor variations may be attributed to various relaxations of $\mathrm{SiOSi}$ chains in the network. No change in $\mathrm{SiH}$ contents from FTIR spectra are detected even after prolonged stay in ambient conditions (6 months), which shows that $\mathrm{Si}-\mathrm{H}$ bond in PMHS gel is very stable. We can conclude that the thin films have a good thermo-oxidative stability. The hydrophobic behavior of the material probably preserves the layer from eventual adsorption of water.

\section{Surface and mechanical properties of thin films}

The thin-films show a high hydrophobic behavior, which is related to the quasi absence of residual $\mathrm{SiOH}$ in the gel. The value of the water contact angle is $105-107^{\circ}$ for the PMHS90. Curing does not significantly modify the value. By changing the $\mathrm{DH} / \mathrm{TH}$ composition from $90 / 10$ to $50 / 50$, the contact angle decreased by less than $5^{\circ}$ showing that the effect of the various $\mathrm{Si}-\mathrm{H}$ and $\mathrm{Si}-\mathrm{CH}_{3}$ content is negligible on the surface energy. The small decrease of the contact angle, with the proportion of trifunctional unit $\mathrm{TH}$, can be related to the higher density of polar siloxane groups $\mathrm{Si}-\mathrm{O}$ in high crosslinked material as evidenced by FTIR spectroscopy.

The glass transition temperature of PMHS90 is about $-120^{\circ} \mathrm{C}^{4}$ Then, at room temperature, the prepared samples are expected to be in an elastomeric state. Neglecting a small amount of remaining cycles in the samples, the 3D network can be characterized by the number of segments between crosslinks, $v^{25}$ :

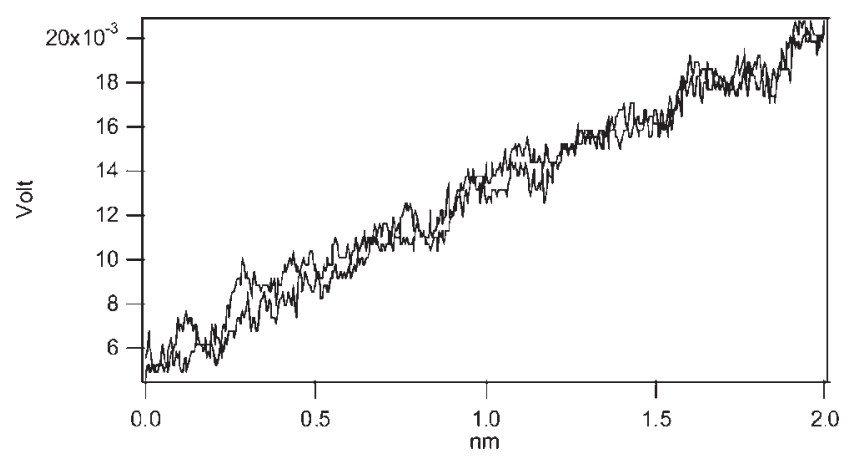

Figure 7 Lateral force - lateral displacement cycle for a cured film of thickness of about $1 \mu \mathrm{m}$ with a $\mathrm{DH} / \mathrm{TH}$ ratio equal to 0.98 , obtained with a scan perpendicular to the axis of the cantilever at a frequency of $2 \mathrm{~Hz}$ and at zero normal load.

$$
v=\frac{2}{f \mu}
$$

where $f=3$ is the functionality of the crosslinkers and $\mu$ stands for their number. Then for a mixture $\alpha /(1-\alpha)$ of $\mathrm{DH} / \mathrm{TH}$, the average number of monomers between two crosslinkers is $2 \alpha / 3(1-\alpha)$. This relation naturally holds when this length is found to be larger than a few units but smaller than the entanglement distance, which is about 220 units in PDMS. ${ }^{26,27}$ In the rubber regime, the Young's modulus scales as the inverse of the molecular weight between crosslinks. ${ }^{25}$ Then the following scaling law is expected between the Young's modulus of the layers $E$ and the crosslinker content $\alpha$ :

$$
E \propto \frac{1-\alpha}{\alpha}
$$

From this relation, it can be concluded that elastic properties of the materials can easily be tuned by controlling the $\mathrm{DH} / \mathrm{TH}$ ratio.

To test the elastic properties of the films, lateral stiffness of the contact is evaluated by recording the torsion signal (friction signal) while scanning over a very low size $(2 \mathrm{~nm})$ perpendicular to the cantilever axis. ${ }^{15}$ Such a small scan size assures that the tip does not slide over the surface, but remains in a static friction response. As shown in Figure 7, the lateral force versus lateral displacement cycles are closed, indicating a purely elastic response of the samples. This is consistent with the fact that layers are in the rubbery regime, far above the glass transition. The slopes of the cycles (Fig. 8) are, at least, ten times lower than the equivalent slope measured on a bare silica surface $(300 \mathrm{mV} / \mathrm{nm})$. This indicates that the contact lateral stiffness is negligible as compared to the cantilever torsional spring constant. Then, the slope of these curves is proportional to the contact lateral stiffness. ${ }^{15}$ This stiffness scales both with the 


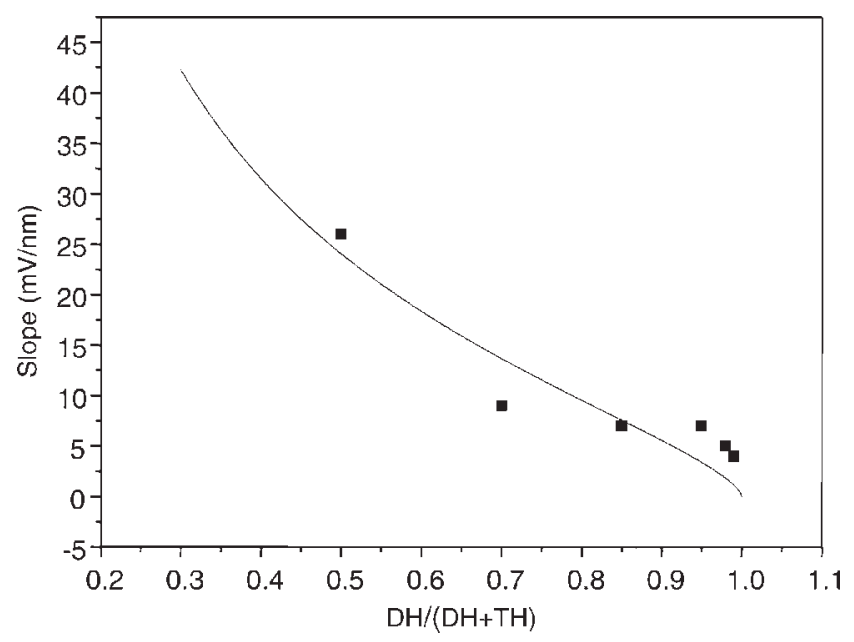

Figure 8 Slope of the lateral force - displacement cycles in a static friction regime $(2 \mathrm{~nm})$ versus the composition of cured films $[\mathrm{DH} /(\mathrm{DH}+\mathrm{TH})$ ratio] of thickness of about 1 $\mu \mathrm{m}$ : dark squares. This slope represents the lateral stiffness of the contact. The expected scaling law for this stiffness [eq. (3)] is represented in continuous line.

contact radius and the Young's modulus of the materials. $^{28}$ In these experiments, the latter is unknown. Under zero normal load, the contact size is controlled by the adhesion between the tip and the sample. As the precise tip radius is also unknown, a comparative evaluation of the modulus will not be attempted here. However, main adhesive contact theories ${ }^{28}$ (DMT and JKR) predict that contact radius scales as the inverse of the third root of the Young's modulus. Then, taking into account the relation (2), the measured stiffness $k$ is expected to scale as

$$
k \propto\left(\frac{1-\alpha}{\alpha}\right)^{2 / 3}
$$

On Figure 8 are displayed the values of the slope for different compositions, ranging from 0.5 to 0.99 . As expected, the slope decreases with increasing $\mathrm{DH}$ content, indicating that the elastic modulus also decreases. The above scaling law is also shown. A qualitative agreement is observed, which validates the above analysis.

\section{CONCLUSIONS}

Thin film coatings with tunable crosslinked ratio $\mathrm{DH} / \mathrm{TH}$ and controlled thickness from nanometer to micrometer range were prepared using dip-coating procedure. We showed that sol-gel reactions can produce fully crosslinked gels as it is expected when using alkoxide precursors containing $\mathrm{Si}-\mathrm{H}$ functionalities. $^{1,4}$ It results in surface-attached networks anchored to the substrate: After surface attachment and crosslinking, thin film cannot be removed from the surface, even by rigorous extraction with boiling organic solvent. Homogeneous or gradient-thickness coating can be produced in this way.

The high hydrophobic behavior of thin films, as measured using contact angle with water, is related to the quasi absence of residual $\mathrm{SiOH}$ in the gel, which is quite correlated with NMR powders characterizations. Indeed, the obtained network in the powdered gels can be described as a fully condensed copolymer by short PMHS chains crosslinked by TH units. Almost no uncondensed $\mathrm{Si}-\mathrm{OEt}$ or $\mathrm{Si}-\mathrm{OH}$ species were found. Moreover, NMR studies indicate the formation of homogeneous system without strong phase separation. As mentioned previously, partial cleavage of $\mathrm{Si}-\mathrm{H}$ bonds of $\mathrm{DH}$ and $\mathrm{TH}$ units occurred in the powdered gels. FTIR spectra of thin film confirmed that the surface-attached networks have similar structures.

We showed that oligomeric linear and small cyclic species can be trapped but noncrosslinked in the network. However, the trapped species were easily extracted from surface-attached network by washing with organic solvents, which induce swelling of the network. This purification is necessary for further characterization of the properties of the material, because trapped species could act as plasticizer leading to various disparities in mechanical properties for instance.

The degree of crosslinking and thus elasticity of the films are easily tuned by changing the $\mathrm{DH} / \mathrm{TH}$ composition. The lateral stiffness measurements, performed for a series of composition, clearly indicate that elastic properties can be finely tuned by changing the crosslinker concentration.

We think that design and control of thin-films with a gradient thickness may have potential applications in material science. ${ }^{19,20}$ Finally, surface-attached polymer network bearing $\mathrm{Si}-\mathrm{H}$ functionalities also interestingly have potential for further postfunctionalization via hydrosilation with alkene. ${ }^{7,8}$ Using the hydrosilation chemistry, molecules could be immobilized into the surface-attached network for specific coating applications. In this respect, the control of the characteristic mesh size of the gel may be an advantage for membrane applications. Work is in progress in these directions.

C. Sanchez is thanked for helpful discussion before starting this study as well as F. Babonneau who gave us useful NMR informations. E. Petit and M. Lopez are thanked for their technical assistance in liquid NMR and ATG experiments. E. Tronel-Perroz is thanked for contact angle measurements. Students G. Nasr and H. Bestal are particularly thanked for their help.

\section{References}

1. Gualandris, V.; Babonneau, F.; Janicke, M. T.; Chmelka, B. F. J Sol-Gel Sci Technol 1998, 12, 75. 
2. Pauthe, M.; Phalippou, J.; Corriu, R.; Leclercq, D.; Vioux, A. J Non-Cryst Solids 1989, 113, 21.

3. Schaudel, B.; Guermeur, C.; Sanchez, C.; Nakatani, K.; Delaire, J. A. J Mater Chem 1997, 7, 61.

4. Sorarù, G. D.; D'Andrea, G.; Campostrini, R.; Babonneau, F. J Mater Chem 1995, 5, 1363.

5. Loy, D. A.; Baugher, B. M.; Baugher, C. R.; Schneider, D. A.; Rahimian, K. Chem Mater 2000, 12, 3624.

6. Pluedemann, E. P. Silane Coupling Agents; Plenum: New York, 1982.

7. Pesek, J. J.; Matyska, M. T. J Sep Sci 2005, 28, 1845.

8. Thami, T.; Barboiu, M.; Nasr, G., to appear.

9. Belot, V.; Corriu, R. J. P.; Leclercq, D.; Mutin, P. H.; Vioux, A. J Polym Sci Part A: Polym Chem 1992, 30, 613.

10. Belot, V.; Corriu, R.; Leclercq, D.; Mutin, P. H.; Vioux, A. Chem Mater 1991, 3, 127.

11. Smith, A. L. Chemical Analysis, Vol. 112: The Analytical Chemistry of Silicones; Wiley: New York, 1991.

12. Brinker, C. J.; Frye, G. C.; Hurd, A. J.; Ashley, C. S. Thin Solids Films 1991, 201, 97.

13. Brinker, C. J.; Scherer, G. W. Sol-Gel Science, the Physics and Chemistry of Sol-Gel Processing; Academic Press: Boston, 1990.

14. Edward, P. Handbook of Optical Constants of Solids; Academic Press: London, 1985.
15. Basire, C.; Fretigny, C. Eur Phys J Appl Phys 1999, 6, 323.

16. Frye, C. L.; Collins, W. T. J Am Chem Soc 1970, 92, 5586.

17. Babonneau, F.; Gualandris, V.; Maquet, J.; Massiot, D.; Janicke, M. T.; Chmelka, B. F. J Sol-Gel Sci Technol 2000, 19, 113.

18. Gupta, S. P.; Moreau, M.; Masure, M.; Sigwalt, P. Eur Polym J 1993, 29, 15.

19. Meredith, J. C.; Smith, A. P.; Karim, A.; Amis, E. J. Macromolecules 2000, 33, 9747.

20. Meredith, J. C.; Karim, A.; Amis, E. J. MRS Bull 2002, 27, 330.

21. Legrand, A. P. The Surface Properties of Silicas; Wiley: Chichester, UK, 1998.

22. Brzoska, J. B.; Azouz, I. B.; Rondelez, F. Langmuir 1994, 10, 4367.

23. Evmenenko, G.; Yu, C. J.; Kmetko, J.; Dutta, P. Langmuir 2002, $18,5468$.

24. Helmy, R.; Wenslow, R. W.; Fadeev, A. Y. J Am Chem Soc 2004, 126, 7595

25. Marks, J. E.; Ermann, B. Rubberlike Elasticity a Molecular Primer; Wiley: New York, 1988.

26. Langley, N. R.; Ferry, J. D. Macromolecules 1968, 1, 353.

27. Souheng, W. J Polym Sci Part B: Polym Phys 1989, 27, 723.

28. Johnson, K. L. Contact Mechanics; Cambridge University Press: Cambridge, MA, 1985. 